\title{
Analysis and Research on the Relationship Between Educational Investment, Economic Development and Poverty Alleviation in Middle-income countries
}

\author{
Qi Zijing ${ }^{1}$, NieYu Beibei², Zong Zhen ${ }^{2}$ \\ ${ }^{1}$ Normal School of Vocational and Technical Education, Hubei University of Technology, Wuhan, Hubei, 430068 \\ ${ }^{2}$ School of Economics, Wuhan Donghu University, Wuhan, Hubei, 430212 \\ vj162774@163.com
}

\begin{abstract}
It is very important to pay attention to the spillover effect of education sector on economic growth. This paper uses the modified Feder model to empirically study the total effect and spillover effect of education investment on economic growth in China. The results show that the spillover effect of education sector on economic growth estimated by the modified Feder model is significant in each period, and this spillover effect is higher than the world average. However, the marginal productivity of China's education sector is relatively low, and this marginal productivity is lower than the world average. Therefore, to develop rural education and improve the level of culture and human capital of peasant household members is an effective way to get rid of poverty and block intergenerational transmission, and it also plays a fundamental and long-term role. Through the investigation and analysis of the economic and educational development of peasant households in the core areas of poverty-stricken areas in Northwest China, it is found that the income/consumption structure of peasant households is single, and the economic burden of educational investment is heavy. Econometric model can be used to demonstrate education investment and other capital investment. Granger causality test shows that there is a long-term and stable two-way causal relationship between economic growth and education investment in poor areas, while economic development is certain. The role of other capital input, labor input and technological progress is regarded as constant $\mathrm{C}$, and step by step to promote the investment of higher vocational education, the two complement each other and cause and effect each other.
\end{abstract}

Keywords: Educational Investment, Economic Development, Poverty Alleviation, Middle-income Countries

\section{INTRODUCTION}

Education investment of spillover effect on economic growth has been one of hot problems in the research of scholars both at home and abroad, Lucas (RobertE. Lucas) put forward the model of two departments in 1988 [1] and Romer (PaulM. Romer) knowledge driven model proposed in 1990 [2] are discussed from the point of view of human capital surplus of the internal mechanism of economic growth, Lucas and Romer model of human capital is mainly formed by education investment, so the Lucas model and Romer's knowledge driven model of two departments created the spillover effect of education investment, it also provides an important reference for studying the spillover effect of education investment on economic growth[3]. The 19th National Congress of the CPC paid great attention to the development of education and proposed to accelerate the process of educational modernization.

As early as 2011, the CPC Central Committee and The State Council issued the Outline of Poverty Alleviation and Development in China's Rural Areas (2011-2020), which explicitly required contiguous poverty-stricken areas to be the main battlefield of poverty alleviation and the top priority of targeted poverty alleviation. The contiguous poverty-stricken areas in northwest China include 24 counties in three prefectures in southern Xinjiang, 61 counties in Liupan Mountain Area, 7 counties in Luliang Mountain area, 38 counties in Qinba Mountain area and 42 counties in Tibetan areas in four provinces, accounting for a total of 172 counties, accounting for $25 \%$ of the whole country[4]. According to the 2016 Rural Poverty Monitoring Report of China released by the Household 
Survey Office of the National Bureau of Statistics, in 2015 , the number of rural poor in the five contiguous poor areas in Northwest China was 7.73 million, accounting for $26.89 \%$ of the rural poor in the contiguous poor areas in China, with an average poverty incidence of $15.15 \%$. The per capita disposable income of rural permanent residents is 6,833 yuan, and the per capita consumption expenditure is 5,875.2 yuan, which is significantly lower than that of rural permanent residents in contiguous poverty-stricken areas $(7,525$ yuan and 6,573 yuan, respectively). From the perspective of labor force distribution industry, $83 \%$ of female labor force and $62 \%$ of male labor force are mainly distributed in the primary industry[5]. In the overall poverty alleviation fund, the funds directly or indirectly used to support the rural economic development account for $40 \%$, while the educational poverty alleviation fund mainly for the construction of rural primary and secondary schools accounts for only 3.7\%.Due to the poor geographical environment and the lack of culture, human resources and other capital among the poor, the population structure in the contiguous poverty-stricken areas is difficult to change and the cycle is long, and the intergenerational transmission of poverty in economic and educational aspects is obvious. Property implantation economic poverty alleviation can help poor families to improve their economic level and get rid of poverty in the short term, but it cannot fundamentally solve the poverty trap of returning to poverty due to weak subsequent development[6].

Because the educational products produced by the education department have the nature of public goods and play a great role in promoting the emergence and diffusion of new knowledge and technology, it is not difficult to draw a conclusion in theory that education has a positive spillover effect on economic growth. However, what is the spillover effect of education on economic growth is also a question worth studying. At the same time, although education has a positive spillover effect on economic growth, the marginal productivity of the education sector is not necessarily higher than that of the non-education sector, so the comparison of factor productivity between the education sector and the non-education sector also has a strong research significance. This paper attempts to introduce human capital into the Feder model and modify the model. On this basis, the modified Feder model is used to measure the spillover effect of education investment on economic growth and the difference of factor productivity between education and non-education sectors, and discusses the impact of education popularization on the process of poverty alleviation.

\section{MODEL BUILDING}

\subsection{Description of specimens}

The article divides the whole national economic sector into two sectors: education and non-education. The production functions of these two sectors can be expressed as:

$$
\begin{gathered}
A=F\left(K_{1}, L_{1}, H_{3}\right) \\
B=G\left(K_{n}, L_{n}, H_{e}, E\right)
\end{gathered}
$$

In the formula, $A$ and $B$ respectively represent the output of the education sector and other non-education sectors, $\mathrm{K}, \mathrm{L}$ and $\mathrm{H}$ respectively represent the material capital, labor force and human capital elements, and the subscript represents the $\mathrm{K}, \mathrm{L}$, and $\mathrm{H}$ can be expressed as

$$
\begin{aligned}
K & =K_{n}+K \\
L & =L_{n}+L \\
H & =H_{n}+H
\end{aligned}
$$

The total output of the national economy $\mathrm{Y}$ is the sum of the two sectors:

$$
Y=E+N
$$

The relationship between labor and marginal productivity of capital in different sectors is expressed as:

$$
\frac{F_{1}}{G_{1}}=\frac{F_{2}}{G_{2}}=\frac{F_{3}}{G_{3}}=1+\delta
$$

On type, $F_{1}, G_{1}, F_{2}, G_{2}, F_{3}$ and $G_{3}$ respectively labor, physical capital and human capital respectively in the marginal productivity of two departments, the $\delta$ is element marginal productivity difference between two departments, in theory, can be greater than, equal to or less than zero, if less than zero means that the education department of marginal productivity is lower than the education department.

By taking the total differential of equations (1) and (2), and combining equations (6) and (7), the following regression equation can be obtained:

$$
\frac{d Y}{Y}=\alpha\left(\frac{d K}{Y}\right)+\beta\left(\frac{d L}{Y}\right)+\lambda\left(\frac{d H}{Y}\right)+\gamma \frac{d E}{E} \frac{E}{Y}
$$

DK is the increment of capital stock, but $d K$ does not exist in the statistics. It is similar to domestic investment I, so the common practice is to replace $d K$ with $I$. So equation (8) can be rewritten as:

Suppose the marginal output of the education sector to the non-education sector is:

$$
G_{1}=\frac{\partial G}{\partial E}=\theta\left(\frac{N}{E}\right)
$$

By substituting Equation (9) into Equation (8), equation (9) can be written as:

$$
\begin{array}{r}
\frac{d Y}{Y}=\alpha\left(\frac{I}{Y}\right)+\beta\left(\frac{d L}{Y}\right)+\lambda\left(\frac{d H}{Y}\right)+\left[\frac{\delta}{1+\delta}+\theta\left(\frac{N}{E}\right)\right] \times\left(\frac{d E}{E}\right)\left(\frac{E}{Y}\right)(10) \\
\text { Combined with Formula (6) and adjusted again, then: } \\
\frac{d Y}{Y}=\alpha\left(\frac{I}{Y}\right)+\beta\left(\frac{d L}{Y}\right)+\lambda\left(\frac{d H}{Y}\right)+\left[\frac{\delta}{1+\delta}+\theta\right]\left(\frac{d E}{E}\right)\left(\frac{E}{Y}\right)+\theta\left(\frac{d E}{E}\right)
\end{array}
$$


Equation (9) and equation (11) are the estimation equations of the paper. If the coefficient in equation (9) is estimated, the total effect of education on economic growth can be obtained; if and in equation (11) are estimated, the effect of education spilt and the marginal factor productivity difference between sectors can be obtained. Since the output value of the education sector only accounts for a small part of the entire national economy, the spillover effect of the education sector on the non-education sector can be regarded as the spillover effect of the education sector on economic growth. Therefore, the improved Feder model can be used to estimate: first, the spillover effect of the education sector on economic growth; Second, the difference in factor productivity between the educational and non-educational sectors.

The output of the education sector E is expressed by the total expenditure on education nationwide, the output of the national economy $\mathrm{Y}$ is expressed by the GROSS domestic product (GDP), the labor force L is expressed by the total number of employees, the fixed asset investment $\mathrm{I}$ is expressed by the fixed asset investment of the whole society, and the growth rate of the total output $d Y / Y$ is GDP calculated at comparable prices growth rate. The research of this paper faces an important problem, which is the measurement of human capital. However, there is no accurate method to measure human capital so far. After several attempts, the calculation method of human capital $\mathrm{H}$ adopted in this paper is as follows: that is, the average number of years of education per employee in each period from 1980 to 2018 multiplied by the number of all employees, and the stock of human capital in each period from 1980 to 2018 can be obtained

\subsection{The relationship between household income/consumption structure, poverty and education input}

The household income/consumption structure and its relationship are not only indicators of a family's economic status and living standard, but also a measure of or a measure of how poor a family is.In terms of family income, the average annual total income of poor households was 6,769.91 yuan in 2015, and the average annual net income per capita was 1,572.86 yuan. The average annual total income of non-poor households was 19,868.09 yuan, and the per capita annual net income was 4,101.21 yuan, 2.93 times and 2.61 times that of poor households, respectively. The income difference between poor households and non-poor households is obvious. In terms of major consumption, food expenditure and education expenditure for poor households accounted for 60.19 percent and 48.33 percent of total household income, respectively, and non-poor households accounted for 24.91 percent and 18.02 percent of total household income, respectively. From family income and food expenditure, while the poor and the poor, in per capita food expenditure, the average family education expenditure and education expenditure per capita amount of the difference is not obvious, but as a result of poor family year income is low, the significant proportion of total expenditure, poor food costs and education spending two combined beyond family year income $8.53 \%$, belong to deficit spending.

According to China's current poverty measurement index, refer to the rural poverty measurement standard of China's Rural Poverty Monitoring Report, we express food consumption/expenditure as a function of total household income, household characteristics and regional characteristics, as follows:

$$
F E=f(\operatorname{InC}, H, D)
$$

Where, represents food consumption expenditure, represents total household income, represents family characteristics, represents regional characteristics. Based on this, the model of the relationship between total household income, household food consumption and household poverty is established as follows (Figure 1) :

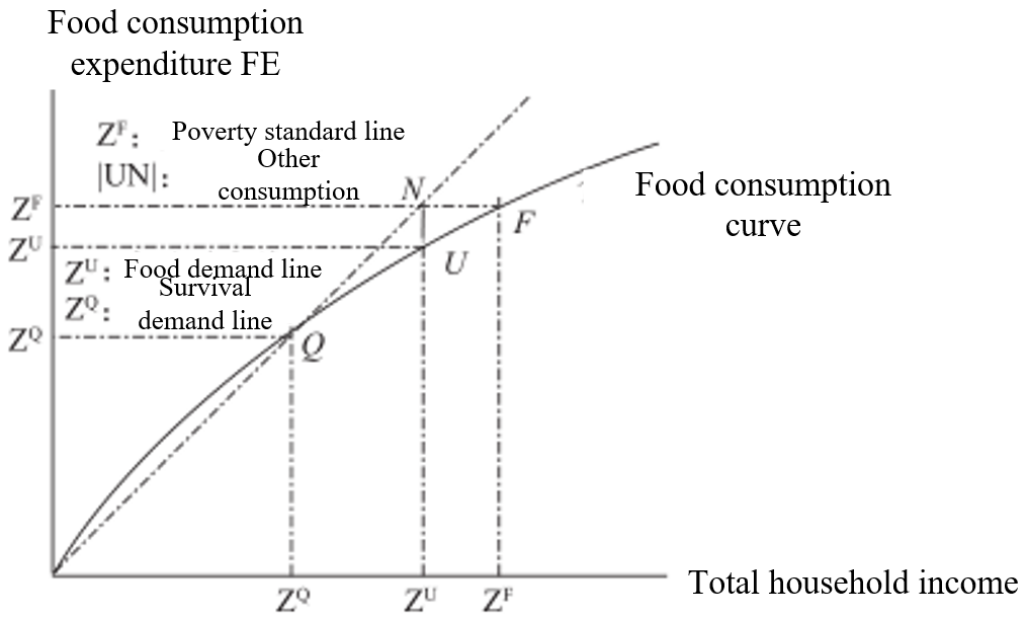

Fig.1 Model of the relationship between household income/consumption and poverty 


\section{ESTIMATION RESULTS}

By Chow dividing Point inspection (Chow Break Point Test), can be obtained for the first equation, the $\mathrm{P}$ statistics is 0.0029 , far less than the critical value of 0.05 , for the second equation, it shows that can be used as a
Point of division in 1992, the sample can be the overall time period is divided into 1980-1992 and 1992-2018 year two time to study. In this paper, EViews7.0 software was used to conduct OLS estimation of equation (9), and the results are shown in Table 1.

Tab.1 Estimated results

\begin{tabular}{|c|c|c|c|c|c|c|c|}
\hline Time & & $I / Y$ & $d L / Y$ & $d H / Y$ & $d E / Y$ & $\mathrm{R}^{2}$ & DW \\
\hline \multirow{3}{*}{ 1908-1992 } & - & 0.55 & $-0,04$ & -0.01 & 4.56 & \multirow{3}{*}{0.61} & \multirow{3}{*}{1.82} \\
\hline & - & (6.39) & $(-0.54)$ & $(-0.09)$ & $(1.05)$ & & \\
\hline & - & {$[0.00]$} & [0.60] & [0.35] & {$[0.32]$} & & \\
\hline \multirow{3}{*}{$1992-2018$} & -0.22 & $(1.52)$ & 10.52 & -0.09 & 24.33 & \multirow{3}{*}{0.71} & \multirow{3}{*}{1.72} \\
\hline & $(-2.21)$ & {$[0.16]$} & $(2.31)$ & $(-0.32)$ & $(2.80)$ & & \\
\hline & [0.05] & 0.23 & {$[0.04]$} & {$[0.76]$} & {$[0.02]$} & & \\
\hline \multirow{3}{*}{$1980-2018$} & - & 0.23 & 0.08 & 0.01 & 8.99 & \multirow{3}{*}{0.06} & \multirow{3}{*}{0.63} \\
\hline & - & (2.79) & $(0.63)$ & $(0.31)$ & (1.48) & & \\
\hline & - & {$[0.03]$} & [0.53] & [0.76] & {$[0.15]$} & & \\
\hline
\end{tabular}

As can be seen from the test results, equation (9) lacks an independent variable $\mathrm{dE} / \mathrm{E}$ in all three time periods, that is to say, equation (9) is only of theoretical significance, but it is difficult to estimate the coefficient value of equation (9) by measurement method. From the regression results, the values of the total contribution of education to economic growth in 1980-1992, 1992-2018 and 1980-2018 were estimated at 4.56, 24.33 and 8.99, respectively. EViews7.0 was used for OLS estimation of equation (11), and for convenience of comparison, OLS estimation was also performed for equation (11) without human capital

Tab.2 Estimated results

\begin{tabular}{|c|c|c|c|c|}
\hline Time & $F$ & $P$ & $L R$ & $P$ \\
\hline $1980-1992$ & 1.97 & 0.20 & 2.86 & 0.09 \\
\hline $1992-2018$ & 17.12 & 0.00 & 15.98 & 0.00 \\
\hline $1980-2018$ & 36.80 & 0.00 & 26.55 & 0.00 \\
\hline
\end{tabular}

The results show that the spillover effect of education sector on economic growth is relatively large. Therefore thinks education department of the spillover effect on economic growth is bigger reason: the education products offered by education department is in the nature of public goods, in particular, provided by the department of education directly products including basic education products and the basic education, but some colleges and universities and research institutions to provide the basis of research products, test development and applied research is provided by the department of education indirect product. Basic education products, basic research products and experimental development are pure public goods, while non-basic education products and applied research products are quasi-public goods, which determines that the products provided by the education sector have a large external effect, so the education sector has a large spillover effect on economic growth.

The income/consumption structure of peasant households is single and the development difference between poor households and non-poor households is obvious. The poverty level of the poor households is deeper, and the economic burden of education input is heavier, but the input intensity is gradually increased. The comparative analysis of the development of poor households and non-poor households shows that due to the relatively single structure and source of main income items, low income and instability, poor households have a heavy economic burden in food and education expenditure, and the poverty relation function FE shows that the poverty level is deep. But from the distribution of the amount and proportion of education expenditure, the poor families are also gradually strengthening the investment in their children's education.

The positive effect of education in promoting the economic development of peasant households is remarkable. Poor households low level of human capital, human resources structure elements The difference and its intergenerational transmission are obvious, and the problem of population aging is serious. From the intergenerational transmission of human capital structure elements and differences, the human resource structure of non-poor households is obviously superior to that of poor households. The low level of human resources in poor households is mainly due to the low education level of family members and unreasonable age structure $(\triangle \mathrm{Yt}=26.31)$.Poor households have an older, less educated workforce, poor health, a smaller workforce in prime age, and a serious problem of aging. OLS regression analysis of the main labor force and total household income of households shows that the education level of family members has a significant positive effect on the economic development of 
households, while it has a higher promotion effect on non-poor households. The main causes of poverty in different households are basically the same, but the attribution tendency is obviously different.We are satisfied with the targeted poverty alleviation efforts and methods, but lack of targeted supply, and lack of targeted "wisdom support" and "ambition support".Both poor and non-poor households believe that poor natural conditions, large medical expenditure, lack of funds, low educational level and lack of technology are the main factors causing poverty. The former is more inclined to attribute poverty to objective conditions, while the latter is more attributed to subjective factors. Although the economic burden of education expenditure of poor households is heavy, they do not think it is the main factor causing poverty subjectively.

\section{CONCLUSION}

Through empirical analysis, the following conclusions can be drawn: The education sector promotes the generation and diffusion of new knowledge and technology, which has a greater spillover effect on economic growth. Compared with the world average, China's education sector has a greater spillover effect on economic growth. Compared with the results without human capital, the spillover effect of education sector on economic growth is larger in each time interval. China's education sector has a greater spillover effect on economic growth than the world average, and its marginal productivity is lower.

Poor families have weak human resources, weak potential for subsequent development, severe population aging, and significant differences from non-poor families in development.The specific educational needs for poverty alleviation are high and concentrated.
Therefore, we should combine poverty alleviation through education with economic poverty alleviation, accelerate the reform of rural education for all, implement the plan of "education downward", and promote the accurate service of education entering villages and households

\section{REFERENCES}

[1] Dalit Contini,Guido Salza. Too few university graduates. Inclusiveness and effectiveness of the Italian higher education system[J]. SocioEconomic Planning Sciences, 2020.

[2] $\mathrm{Li}$ An. Difficulties and Countermeasures of Educational Economy and Management Discipline Development[A]. .Proceedings of 2019 7th International Education,Economics,Social Science,Arts,Sports and Management Engineering Conference(IEESASM 2019)[C].:,2019:5.

[3] Zhang Qirong. Analysis of the factors influencing the economic benefits of higher education $[\mathrm{J}]$. Adult Education in China, 2020 (05).

[4] Wang Jieru. Thoughts on the future development of educational economic management major $[\mathrm{J}]$. Journal of Pu'er College, 2017 (06).

[5] Zhang Jingshuang. Research on the contribution rate of higher Education to Economic growth in Jilin Province [D]. Liaoning University, 2017.

[6] Cao Chueh. The predicament and Countermeasures of the Development of Educational economy and Management discipline [J]. Modern Economic Information, 2017 (03). 